\title{
EDITORIAL
}

\section{The haemodynamic effects of morphine}

Morphine is often assumed to be a peripheral veno-dilator and a reduction in venous return to be the reason for its efficacy in acute pulmonary oedema. A group of allied workers investigated this hypothesis and were able to draw some definite conclusions. Vismara et al. (1976) studied the effects of venous tone in the forearms of patients with pulmonary oedema. They concluded that 'since the drug morphine sulfate (sic) does not cause a major pooling of blood in the limbs, the favourable effect of narcotics in patients with pulmonary edema (sic) must be caused by other mechanisms such as splanchnic pooling, afterload reduction or reduced breathing effort.' In the same year, Lee $e t$ al. (1976) compared the effects of morphine, meperidine and pentazocine on the haemodynamic status of patients with acute myocardial infarction. They could demonstrate no significant haemodynamic effect (including any change in pulmonary capillary wedge pressure) of either morphine or meperidine. Pentazocine, however, increased systemic and arterial pressures, left ventricular filling pressure and systemic vascular resistance. It decreased left ventricular ejection fraction. These workers again commented on the commonly held belief that morphine was a peripheral veno-dilator and referred to other publications of the group in which they had concluded a central sympatholytic role for morphine (Zelis et al., 1974; Mansour et al., 1970).

There is no doubt that morphine is the analgesic of choice in severe, ischaemic chest pain (Newland, 1986). It is also extremely effective in relieving the dyspnoea associated with acute left ventricular failure and pulmonary oedema. However, the concept of a 'medical phlebotomy' has not been proven and the benefits of morphine are likely to lie more in its central sympatholytic and anxiolytic properties.

\section{A. D. REDMOND \\ Editor}




\section{REFERENCES}

Lee G., DeMaria A.N., Amsterdam E.A., Realyvasques M., Angel J., Morrison S. \& Mason D. T. (197\$ Comparative effects of morphine, meperidine and pentazocine on cardiociculatory dynamics in patient with acute myocardial infarction. American fournal of Medicine 60, 949-55.

Mansour E., Capone R. \& Mason D. T. (1970) The mechanism of morphine-induced peripheral arteriolas dilation-central nervous sympatholysis. American fournal of Cardiology 26, 648.

Newland M. C. (1986) Choice of analgesics for cardiac pain relief. In Cardiovascular emergencies, Ornato J. (ed.). Edinburgh, Churchill Livingstone.

Vismara L. A., Leaman D. M. \& Zelis R. (1976) The effects of morphine on venous tone in patients with acuge pulmonary edema. Circulation 54, 335-7.

Zelis R., Mansour E. J., Capone R. J. \& Mason D. T. (1974) The cardiovascular effects of morphine: the peripheral capacitance and resistance vessels in human subjects. Fournal of Clinical Investigation 54, 1247 51. 